\begin{tabular}{|l|l|l||}
\hline \multicolumn{2}{|c|}{ PublisherInfo } \\
\hline \hline PublisherName & $:$ & BioMed Central \\
\hline \hline PublisherLocation & $:$ & London \\
\hline \hline PublisherImprintName & $:$ & BioMed Central \\
\hline \hline
\end{tabular}

\title{
Swiss computing center opens
}

\begin{tabular}{|l|l|l||}
\hline \multicolumn{2}{|c|}{ ArticleInfo } \\
\hline \hline ArticleID & $:$ & 4946 \\
\hline \hline ArticleDOI & $:$ & $10.1186 /$ gb-spotlight-20040428-02 \\
\hline \hline ArticleCitationID & $:$ & spotlight-20040428-02 \\
\hline \hline ArticleSequenceNumber & $:$ & 298 \\
\hline \hline ArticleCategory & $:$ & Research news \\
\hline ArticleFirstPage & $:$ & 1 \\
\hline \hline ArticleLastPage & $:$ & 2 \\
\hline \hline & & RegistrationDate : 2004-4-28 \\
\hline ArticleHistory & $:$ & OnlineDate \\
\hline \hline ArticleCopyright & $:$ & BioMed Central Ltd2004-4-28 \\
\hline \hline ArticleGrants & $:$ & \\
\hline \hline ArticleContext & $:$ & 130594411 \\
\hline \hline
\end{tabular}


A new computing center that will provide life scientists with access to high-performance hardware and a software consulting service has been established by the Swiss Institute of Bioinformatics, the Universities of Lausanne, Geneva, and Basel, l'Ecole Polytechnique Fédérale de Lausanne, and the Ludwig Institute for Cancer Research in Lausanne, in collaboration with Intel Corporation and HewlettPackard (HP).

Inaugurated last Thursday (April 22), the Lausanne-based Vital-IT center is equipped with two HP clusters of 32 production and 8 development servers, based on Intel's Itanium 2 processor. These kinds of clusters allow life scientists to run complicated software 10 to 50 times faster, thereby opening new research avenues, says Christos Ouzounis at the European Bioinformatics Institute. "You can think of problems that you could not think of otherwise if you had a limited computational capacity," he told us.

The impact of the new computing power may soon be felt not only by scientists directly associated with Vital-IT, but by researchers worldwide who use the services available through the Swiss Institute of Bioinformatics, such as proteomics tools on the ExPASy (Expert Protein Analysis System) servers.

The Vital-IT center also employs four information technology specialists who have access to the full technological know-how of Intel and HP. According to the center's director, Victor Jongeneel, a major aim is to develop software for the life sciences that is more robust and that performs better than the current programs, which are often written by people who are not professional programmers.

The new software will run on the Itanium 2 architecture, which has been on the market for 2 years. The technology is particularly suited for large-scale computational problems; however, its uptake has been slow, partly because there is not much software that runs on it.

"We took a chance in deciding to go for machines that have this chip," concedes Jongeneel. "But rather than going with legacy technology, even though it is very fast right now, we [have gone] with technology that is maybe a little more expensive and with a slightly lower performance right now, with the idea that 5 years from now, we will have gone beyond all the problems associated with it, while other centers will be struggling to keep up."

\section{References}

1. Vital-IT Project, Swiss Institute of Bioinformatics, [http://www.isb-sib.ch/projects/vitalit.htm]

2. European Bioinformatics Institute, [http://www.ebi.ac.uk]

3. ExPASy, [http://au.expasy.org/]

4. C. Victor Jongeneel, [http://www.cancerresearch.org/cancervaccines2000/jongeneel.html] 